CDD: 001.644

\title{
MARKETING APLICADO EM BIBLIOTECAS: ANÁLISE DE CONTEÚDO DOS ARTIGOS PUBLICADOS EM PERIÓDICOS DA CIÊNCIA DA INFORMAÇÃO
}

\author{
MARKETING APPLIED IN LIBRARIES: A CONTENT ANALYSIS OF ARTICLES \\ PUBLISHED IN JOURNALS OF INFORMATION SCIENCE
}

Adriana Stefani Cativelli ${ }^{1}$

\begin{abstract}
Resumo: Analisa os artigos publicados em periódicos referentes ao marketing no âmbito das bibliotecas. Visa verificar de que forma as bibliotecas estão utilizando o marketing em suas rotinas, reúne e examina a literatura existente sobre o assunto em questão e verifica qual a ação de marketing é explorada com maior frequência pelas bibliotecas. Caracteriza a pesquisa como documental de natureza exploratória, descritiva e quali-quantitativa. Constitui o corpus de análise com artigos publicados em periódicos nacionais de Ciência da Informação, no período de 2000 a 2011. Analisa os dados, usando como base a técnica de análise de conteúdo proposta por Bardin. Verifica que dentre as diversas ferramentas que o marketing oferece, a mais utilizada pelas bibliotecas é a da filosofia gerencial. Conclui que a adoção do marketing pelas bibliotecas propiciou a realização de trocas com seus usuários internos e externos, com intuito de focar nas necessidades e desejos dos mesmos, além de instigar os gestores a repensar a forma de gerir as unidades de informação.
\end{abstract}

Palavras-chave: Marketing em bibliotecas. Gestão de bibliotecas. Marketing sem fins lucrativos.

\begin{abstract}
Analyses the articles published in Journals, concerning marketing in libraries environment. Aims to verify how libraries are using marketing in their routines, gathers and examines the existing literature on the referred subject and checks which action in marketing is explored more often by libraries. The research is characterized as documentary, of exploratory basis, descriptive, qualitative and quantitative. The corpus of analysis is constituted by articles published in Information Science national journals from 2000 to 2011. Analyzes the data, using as a base, the technique of content analysis, proposed by Bardin. Notes that among the various tools that marketing offers, the most used by libraries is the Philosophy Management. Concludes that the adoption of marketing by libraries provided exchanges with their internal and external users, in order to focus on the needs and desires of these users, besides instigating managers to rethink how to manage the information units.
\end{abstract}

Key-words: Marketing in libraries. Library Management. Non-profit Marketing.

\footnotetext{
${ }^{1}$ Universidade Federal da Fronteira Sul. Brasil. E-mail: drica_cati@ hotmail.com
}

\begin{tabular}{|l|l|l|l|l|r|l} 
(C) Rev. digit. bibliotecon. cienc. inf. & Campinas, SP & v.11 & n.3 & p.30-45 & set./dez. 2013 & ISSN 1678-765X \\
\hline
\end{tabular}




\section{INTRODUÇÃO}

Com as constantes transformações do mundo globalizado, as organizações sofrem com as fortes pressões, tornando seus ambientes instáveis, exigindo delas uma incessante busca de novidades e aprimoramentos que otimizem o seu negócio.

Nesse sentido, as bibliotecas, organizações sem fins lucrativos, também fazem parte do cenário de incertezas. A informação, principal produto que as bibliotecas ofertam através dos mais variados serviços, também é facilmente encontrada através de outros meios, como livrarias e a internet. O usuário que desejar obter a informação escolherá a opção que lhe trouxer melhor custo-benefício. Nesta ótica, é fundamental que os gestores de bibliotecas conheçam a filosofia administrativa voltada para o marketing, tendo em vista adaptá-la e aplicá-la, com a finalidade de tornar estes ambientes, que são estigmatizados há anos, em locais mais atraentes.

O marketing, como ferramenta gerencial, possibilita à biblioteca conhecer o universo em que atua, tanto internamente como externamente, permitindo a criação, desenvolvimento, promoção e distribuição de produtos e serviços de informação. Conforme exposto, esta pesquisa teve como objetivo analisar o conteúdo dos artigos publicados em periódicos da Ciência da Informação, visando verificar de que forma as bibliotecas estão utilizando o marketing em suas rotinas. Com o intuito de atingir o objetivo geral, foram determinados os seguintes objetivos específicos: reunir e examinar a literatura existente sobre o assunto e verificar qual a ação de marketing é explorada com maior frequência pelas bibliotecas.

\section{FUNDAMENTAÇÃO TEÓRICA}

Para compreender a totalidade do significado da palavra marketing, traz-se a definição encontrada na página da American Marketing Association (AMA) (2007, tradução nossa), a qual descreve o marketing como "a atividade, conjunto de instituições e processos para criar, comunicar, entregar e trocar ofertas que têm valor para os consumidores, clientes, parceiros e sociedade em geral." Mostrando que o marketing engloba as empresas com e sem fins lucrativos.

Segundo Churchill e Peter (2010), grande parte dos tipos de marketing podem ser aplicados tanto em empresas que visam ou não lucros. Uma loja pode vender um objeto pelo dobro do valor que o adquiriu e lucrar com isso, assim como uma

\begin{tabular}{|l|l|l|l|l|l|l|}
\hline (C) Rev. digit. bibliotecon. cienc. inf. & Campinas, SP & v.11 & n.3 & p.30-45 & set./dez. 2013 & ISSN 1678-765X \\
\hline
\end{tabular}


fundação pode vender um produto e com o lucro obtido cobrir seus custos. Outra possibilidade de utilização do marketing em organizações sem fins lucrativos é a de atingir metas, como a recuperação de dependentes químicos.

Assim sendo, esta ferramenta revela suas diferentes facetas para que as organizações a utilizem na busca de realizar trocas com seu público-alvo, visando benefícios para ambos.

Neste sentido, o marketing pode revelar-se um grande aliado, não só das empresas que visam o lucro, mas também daquelas que não o visam, como revelam Churchill e Peter (2010) quando mencionam que as estratégias de marketing podem ajudar estas organizações a alcançarem seus objetivos. A justificativa baseia-se no fato de que as organizações sem fins lucrativos também têm metas a cumprir, seja em atingir um número $x$ doações de sangue ou a visita de $y$ pessoas à determinada exposição (CHURCHILL; PETER, 2010). Olhando por este prisma, todas as organizações têm este ponto em comum (metas), mas como revelam os autores, “enquanto a principal meta do marketing para uma empresa é trazer lucros, o marketing em organizações sem fins lucrativos é direcionado para outros objetivos, como incentivar o uso de serviços da organização." (CHURCHILL; PETER, 2010, p. 304).

Trazendo o marketing para o contexto das bibliotecas, Oliveira (1985, p. 146) aponta que "com a mudança de atitude para o marketing, as bibliotecas melhorarão sua imagem, atrairão novos usuários e oferecerão serviços que melhor satisfarão as necessidades da comunidade alvo". Mas como isso seria possível? Kotler e Lee (2007) nos apresentam a ideia de como uma biblioteca aplicaria ferramentas de marketing em sua rotina, implementando o composto de marketing (quadro 3). O qual busca descrever os principais elementos que influenciam nas decisões de marketing para produzir a resposta que se deseja no mercado-alvo (BASTA, 2006)

QUADRO 1: Modelo simplificado do processo de marketing

\begin{tabular}{|l|l|l|l|}
\hline PRODUTO & PREÇO & PRAÇA & PROMOÇÃO \\
\hline $\begin{array}{l}\text { Livros, materiais de } \\
\text { referência, periódicos, } \\
\text { Cds, DVDs, bases de } \\
\text { dados, E-books. Número de } \\
\text { atendentes, condições } \\
\text { ambientais,... }\end{array}$ & $\begin{array}{l}\text { Tempo, esforço,... } \\
\text { Redução de tempo para } \\
\text { retirar um livro, esforço } \\
\text { para encontrar uma vaga de } \\
\text { estacionamento. }\end{array}$ & $\begin{array}{l}\text { Localização física, } \\
\text { estacionamento, horário, } \\
\text { dias da semana com } \\
\text { atendimento ao público, }, \\
\text { operações sendo realizadas } \\
\text { pelos usuários através de } \\
\text { acesso remoto, ... }\end{array}$ & $\begin{array}{l}\text { Programa de leitura de } \\
\text { verão- veículos } \\
\text { promocionais incluiriam a } \\
\text { propaganda, distribuição de } \\
\text { divulgação do } \\
\text { calendário e relatos em } \\
\text { jornal local. }\end{array}$ \\
\hline
\end{tabular}

Fonte: Kotler e Armstrong (2007, p. 4) 


\section{PROCEDIMENTOS METODOLÓGICOS}

A caracterização da presente pesquisa identifica-se como pesquisa documental no que diz respeito as abordagens de marketing no âmbito das bibliotecas. Do ponto de vista dos seus objetivos, a pesquisa caracteriza-se como exploratória e descritiva. Conforme relata Gil (1991), a pesquisa exploratória tem por objetivo oferecer maior familiaridade com o problema de pesquisa, com o intuito de explicitar e construir hipóteses. Neste sentido, foram averiguadas abordagens e intuições que trouxeram como resultados uma visão geral do assunto em questão. Já a pesquisa descritiva, enfatiza Gil (1991, p. 46), permite "descrever as características de determinado fenômeno ou o estabelecimento de relações entre variáveis". No tocante a esta pesquisa descreveram-se as interpretações e experiências de cada escritor, onde foi averiguada relações entre as diferenças e similaridades nos discursos.

No exame dos dados empregou-se o método sugerido por Bardin (1979, p. 43), chamado de análise de conteúdo, o qual possibilita elaborar "uma análise dos resultados de forma quantitativa como também qualitativa, através da descrição dos conteúdos das mensagens e de unidades de registro correspondentes às variáveis categorias da pesquisa".

A análise de conteúdo de Bardin (1979) é composta de três pólos cronológicos. O primeiro é a pré-análise, etapa de organização do material no plano da análise, no qual foram escolhidos os documentos que fizeram parte do corpus da pesquisa, além da elaboração dos objetivos e indicadores que fundamentaram a interpretação final. Tais procedimentos se concretizaram ao longo da leitura superficial e do contato com os documentos.

O segundo diz respeito à exploração do material, fase de "codificação, desconto ou enumeração, em função de regras previamente formuladas." (BARDIN, 1979, p. 101). Nesta etapa os dados brutos são convertidos de forma organizada, possibilitando um relato das características referentes ao conteúdo.

Por fim, a última etapa, o tratamento dos resultados obtidos e interpretação, que é a fase de codificação dos dados brutos em informações significativas e válidas. É neste momento que interpretações e inferências serão concretizadas, além do confronto dos resultados com os objetivos almejados. O corpus do estudo constituiuse de publicações periódicas da área de Ciência da Informação, no qual se utilizou a 
Base de Dados Referencial de Artigos de Periódicos em Ciência da Informação (BRAPCI).

$\mathrm{Na}$ BRAPCI foram selecionados artigos que traziam em seu título resumo ou palavras-chave, os termos pertinentes ao marketing em bibliotecas. A cobertura temporal do corpus foi restringida entre os últimos 12 anos (2000-2011) e a cobertura espacial foi delimitada em território nacional brasileiro.

\section{RESULTADOS}

Tomando como base o modelo categorial, foi possível dividir os trabalhos em oito categorias, conforme segue na Tabela 1.

TABELA 1 - Artigos publicados em ciência da informação de 2000-2012 sobre marketing no âmbito das bibliotecas: categoria de análise

\begin{tabular}{c|c|c|c|c|c|c|c|c|c|c|c}
\hline Categorias/ Anos & 2000 & 2002 & 2003 & 2004 & 2006 & 2007 & 2008 & 2009 & 2010 & 2011 & Total \\
\hline CRM & & & 1 & & 1 & 1 & & & & & 3 \\
\hline $\begin{array}{c}\text { Marketing no contexto } \\
\text { cultural }\end{array}$ & & & & 1 & & & 1 & & & & 2 \\
\hline $\begin{array}{c}\text { Marketing como filosofia } \\
\text { gerencial }\end{array}$ & 2 & & & & & & 2 & & 1 & & 5 \\
\hline Marketing na Internet & 2 & 1 & & & & & & & & & 3 \\
\hline Composto de Marketing & 1 & & & & & 1 & & & & 1 & 3 \\
\hline Promoção e comunicação & & & & & & & 1 & 1 & & 1 & 3 \\
\hline $\begin{array}{c}\text { Marketing de } \\
\text { relacionamento }\end{array}$ & & & & & & & & 1 & & 1 & 2 \\
\hline TOTAL & 5 & 1 & 1 & 1 & 1 & 2 & 4 & 2 & 1 & 3 & 21 \\
\hline
\end{tabular}

Customer Relationship Management (CRM) é um sistema de gerenciamento integrado que busca entender as necessidades e expectativas de seus clientes antecipadamente. Para isso, existem diversas ferramentas e sistemas tecnológicos que auxiliam as organizações a coletar os dados que necessitam sobre seus clientes, para que sirvam como instrumento na tomada de decisão pelos gestores.

Nesta categoria, denominada "gestão de relacionamento com o cliente", foram encontrados três artigos que abordam o tema.

Oliveira e Pereira (2003) realizaram em seu estudo uma retrospectiva sobre o marketing de relacionamento, sugerindo a utilização dos 11 Cs pelas bibliotecas. As variáveis utilizadas nos $11 \mathrm{Cs}$ dizem respeito a: cliente, categorias, capacidades, controle do contato com os processos monetários, colaboração e integração, 
customização, cálculos com o cliente, cuidados com o cliente, cadeia de relacionamentos, custo, lucratividade e valor, e comunicação, interação e posicionamento.

As escritoras defendem a posição de que se a biblioteca passar a ouvir seus usuários e fornecer o pacote de benefícios que eles desejam, estes retribuirão com confiança e lealdade, ocorrendo então a troca. Com o foco na prestação de serviços ao usuário, enfatiza-se "que as unidades de informação (UI) são mais bem vistas pelos serviços que prestam à sua comunidade, do que propriamente, pelos seus acervos." (OLIVEIRA; PEREIRA, 2003, p. 26).

Neves, Souza e Lucas (2006) buscam em seu estudo analisar e compreender a definição da "gestão de relacionamento com o cliente", para posteriormente traçar um comparativo com o módulo usuário dos sistemas de gestão utilizados pelas bibliotecas. $\mathrm{O}$ artigo verificou quais os elementos do CRM estão presentes em três softwares integrados de gestão de bibliotecas. Os autores atentam para os dados que são armazenados no perfil do usuário, sugerindo que deveria existir um local para depositar informações que identifiquem fontes de informação utilizadas, trabalhos realizados e áreas de interesse, para que "após identificar as várias características dos usuários pode-se classificá-los e categorizá-los em pequenos grupos de modo a facilitar o gerenciamento das relações com o usuário." (NEVES; SOUZA; LUCAS, 2006, p. 123).

No terceiro artigo, Lucas e Souza (2007) baseiam-se nos fundamentos do CRM, com vistas à aplicá-los na Disseminação Seletiva da Informação (DSI) nas bibliotecas. Elas apontam que para existir eficiência e eficácia deste serviço, é preciso construir uma estrutura de base de dados ou perfis de interesse que sejam claros e objetivos, onde constem também o feedback por parte dos usuários dos serviços prestados pelas bibliotecas, tornando a DSI personalizada e interativa. Também é destacada a importância de adotar os quatro pilares do CRM no serviço de DSI identificar, personalizar, interagir e personalizar.

Marketing no contexto cultural é denominado como um conjunto de ações de marketing que visa à cultura, também é utilizado para promover o nome, produto ou fixar imagem de uma instituição patrocinadora. Este tipo de marketing não utiliza 
fórmulas específicas, o grande trunfo esta na criatividade.

A categoria "marketing no contexto cultural" obteve dois artigos recuperados. No primeiro, Job (2004) discorre sobre o uso do marketing cultural em bibliotecas públicas do estado do Rio Grande do Sul. A escritora identificou dois projetos produzidos pela Associação Rio-Grandense de Bibliotecários, o Pró-Biblioteca, que visa à distribuição de livros nas bibliotecas públicas escolares, além de incentivar a leitura e o Pró-Leitura, por meio do qual empresas podem adquirir ou doar o número de obras que desejarem para a biblioteca que optarem. Job (2006, p. 458) ressalta que "a despesa que a empresa teria que obrigatoriamente fazer para os cofres públicos através do recolhimento de tributos, é direcionada para a formação cultural da sua comunidade."

Já no segundo artigo, Andretti, Calegaro e Machado (2008) contam a experiência das bibliotecas da Universidade do Vale do Itajaí (UNIVALI), que desenvolveram uma ação cultural como estratégia de marketing. As atividades relatadas foram: mesa literária - cada mês com uma temática, expondo diferentes tipos de materiais; palestras; exposições; hora do conto; lançamentos - livros, apresentações musicais e projeções de filmes; cursos e oficinas; cine clube; apresentações musicais; bibliotecando por aí - balcão itinerante que circula por toda universidade; Vitrine - jornal eletrônico

Marketing como filosofia gerencial busca tratar os artigos mais genéricos sobre o marketing, os quais relataram o marketing como um processo gerencial dentro de suas unidades. As bibliotecas, que estão orientadas para o marketing, têm como filosofia a priorização do atendimento, visando sempre a troca com o usuário. Para isso, elas realizam ações administrativas, com o intuito de atingir seus objetivos.

Esta categoria reuniu cinco trabalhos publicados nas revistas brasileiras da área. No primeiro trabalho, Silva (2000) relata suas impressões, com base na literatura existente da área, sobre a aplicação do marketing em UI. Revela que ainda não há trabalhos suficientes que avaliem os resultados das aplicações de marketing, apontando como:

Um dos obstáculos ao desenvolvimento da literatura de marketing para unidades de informação é que, até o presente momento, pouco se discutiu sobre a natureza do negócio das bibliotecas. A literatura preocupa-se mais 
em entender, absorver e transportar os conceitos de marketing do que analisar o negócio das bibliotecas sob a ótica desses conceitos. (SILVA, 2000, p. 10).

Já Silva, Moreira e Duarte (2000) narram a utilização do endomarketing, que objetiva realizar trocas com seu público interno, buscando fazer com que eles sintamse peças fundamentais, ao compartilhar os objetivos da empresa. Dois seminários foram organizados: um deles, promoveu a comunicação entre os setores da universidade, onde foram apontados críticas e sugestões; e o outro, apresentou a discussão do plano de marketing em elaboração, possibilitando discussões e debates acerca das propostas apresentadas pela equipe do projeto.

No terceiro artigo, Oliveira (2008) apresenta uma análise sobre a importância do planejamento em gestão de bibliotecas, enfatizando o uso de ferramentas de marketing. Para isso foi criado um plano estratégico de marketing, que teve como objetivo divulgar amplamente os serviços e produtos oferecidos pela biblioteca. Inicialmente foi realizado o diagnóstico da situação através de pesquisa ao cliente, após foi elaborado o plano em que foram definidas formas de acompanhamento e, por último, a avaliação que permitiu verificar o sucesso na implementação do plano e traçar novos objetivos e metas (OLIVEIRA, 2008).

Amaral (2008) aborda que as UIs precisam entender o negócio da informação aplicando as técnicas de marketing, ofertando produtos e serviços através da web ou no ambiente tradicional. Um novo perfil de biblioteca deve surgir, a qual "inove em conjunto com todos, sobretudo com os seus usuários, compartilhe recursos que antes eram guardados a sete chaves, utilize o poder da colaboração em massa e se comporte como biblioteca verdadeiramente global." (AMARAL, 2008, p. 65).

Já Dias e Duarte (2010) buscaram analisar o grau de conhecimento, por parte dos clientes internos e externos, a respeito dos produtos e serviços ofertados pela biblioteca. "Os resultados demonstraram que a instituição necessita de ações de marketing e endomarketing" (DIAS; DUARTE, 2010, p. 1), pois tanto funcionários como comunidade acadêmica não conheciam toda gama de serviços ofertados pela biblioteca.

Marketing na internet busca promover produtos e serviços na internet, os 
quais oferecem recursos de baixo custo, possibilitando as empresas atingirem seus clientes a nível mundial. Além de permitir que exista maior interatividade entre cliente e organização.

Nesta categoria foram encontrados três artigos publicados. No primeiro artigo, Araújo (2000) discorre sobre algumas ferramentas que estão disponíveis na web, que segundo a ótica do marketing, podem ser aplicadas na promoção de páginas das UIs. Da mesma forma, são citados: banners - pequenas figuras que ao clicar-se remeterá o usuário a página do conteúdo; selos - são similares aos banners, representam campanhas, instituições ou prêmio; pop-up - nova janela que sobrepõe ao navegador; entre outros.

Amaral (2000, p. 69), no segundo artigo, "destaca as características do ciberespaço como desafio a ser enfrentado pelos profissionais da informação para promover os produtos e serviços de informação oferecidos". Enfatiza o ciberespaço como local propício para oferta de produtos e serviços de informação, trazendo como sua aliada, a teoria de marketing para contribuições significativas.

No terceiro trabalho, Oliveira (2002) enfatiza o uso da internet por parte dos profissionais da informação. Citando a internet, como ferramenta de marketing na resolução de problemas dos usuários, no conhecimento do público-alvo e na exposição de produtos e serviços, estabelecendo um relacionamento estreito com o usuário. A autora também sugere a adoção de algumas ferramentas da web, como: fóruns, bate-papo, lista de mala direta, entre outros.

Composto de marketing também chamado de mix de marketing e 4 Ps, ele é uma combinação dos quatro principais componentes do marketing: produto, praça, promoção e preço. Esses componentes funcionam como pontos de orientação para a organização perseguir e atingir seus objetivos.

A categoria "composto de marketing" obteve três artigos. No primeiro artigo encontrado, Amaral (2000) realizou o levantamento de 60 documentos que tratavam do composto de marketing em UI entre os anos de 1975-1995. O estudo procurou responder: "Quantos autores escreveram sobre os 4Ps? Qual o autor mais produtivo entre eles? Quem foi o pioneiro a escrever sobre os 4Ps em UI? Qual o pioneiro a propor a adição de Ps aos 4Ps?” (AMARAL, 2000, p. 52). 
Já na pesquisa de Lima e Silva, apresentam "o marketing pessoal como uma ferramenta que contribui para o reconhecimento da profissão e valorização do profissional da informação." (2007, p. 1). Os autores utilizam o composto de marketing para demonstrar que o profissional também pode usar esta ferramenta para atingir seus objetivos profissionais, conforme: produto - o profissional e sua formação, capacidade e experiência, entre outros; preço - valor do salário pago aos profissionais na praça; praça/ distribuição - o mercado, estar visível no mercado das oportunidades; promoção - currículo, contato com pessoas influentes no seu meio. Além das variáveis apresentadas, a aparência, higiene pessoal, postura física, forma de se comunicar são de extrema importância.

Angelo e Ziviani (2011) abordam a aplicabilidade do marketing informacional em UI utilizando o composto de marketing. "Os dois primeiros (produto e preço) destinados a atender a demanda e os outros dois (praça e promoção) relativo às vendas e divulgação dos produtos e/ou serviços." (ANGELO; ZIVIANI, 2011, p. 5). A unidade em questão tinha como metas tornar os serviços, produtos e sua imagem mais conhecidos e atraentes, além da ampla divulgação.

Promoção e comunicação são integrantes dos elementos do composto de marketing, a promoção e comunicação são todas as atividades de comunicação que buscam promover a utilização de determinado produto ou serviço. Entre as atividades estão: propaganda, marketing direto, promoções e eventos, relações públicas, boca-a boca, entre outros.

$\mathrm{Na}$ presente categoria, promoção e comunicação, foram recuperados três artigos. Começando com Amaral (2008), que discorre sobre a importância do profissional da informação em conhecer a teoria de marketing para aplicação em sua rotina. É realizado um levantamento da literatura sobre a promoção e a comunicação da informação nas organizações. A autora atesta que:

[...] é uma tentativa de contribuir para o entendimento da necessidade de realizar a ação de promover como atividade de marketing, usando o princípio da comunicação integrada de marketing, que mostra a importância do planejamento e da realização coordenada e integrada das ações promocionais com as de comunicação, ambas voltadas para o 
conceito, filosofia e mentalidade de marketing. (AMARAL, 2008, p. 41).

Já Baptista, Costa e Viana Neta (2009) realizaram a verificação de uso de atividades promocionais de marketing na Biblioteca da Presidência da República. Constataram que "a biblioteca planejou e utilizou várias técnicas de promoção: atmosfera, divulgação dos serviços, relações públicas com projetos destinados a um determinado público, para promover seu relacionamento com o usuário da biblioteca." (BAPTISTA; COSTA; VIANA NETA, 2009, p. 83).

No terceiro trabalho encontrado, Araujo, Silva e Silva (2011) trataram de averiguar se os usuários da Biblioteca Central da Universidade Federal da Paraíba conheciam os serviços prestados pela seção de multimeios (diferentes suportes informacionais), assim como o perfil dos mesmos. Percebeu-se que a grande parte dos usuários não tinha conhecimento, o que revelou a necessidade de ações de marketing voltadas à promoção e à comunicação. Algumas ações adotadas: afixação de quadros em locais estratégicos, envio de e-mail referente a produtos e serviços, confecção de folders, entrega de material promocional ao aluno no ato da matrícula, entre outros. Também primou-se pelo contato pessoal em seminários e visitas dirigidas.

Marketing de relacionamento busca estabelecer relação com os clientes, visando atender aos seus desejos e anseios a fim de fidelizá-los. Para isso, é necessário que a organização conheça e escute seu cliente de forma consistente e periódica.

A categoria "marketing de relacionamento" obteve dois trabalhos publicados. Começando por Rozados e Piffer (2009), elas abordam que as UI precisam buscar conhecer quem são os seus usuários, suas necessidades informacionais, novos hábitos, a fim de oferecer serviços de qualidade. As autoras também traçam um comparativo entre a pesquisa de marketing e o estudos de usuário e concluem:

[...] buscam, prioritariamente, conhecer comportamentos, hábitos, necessidades e demandas de clientes e/ou usuários, tendo como fim não apenas oferecer serviços e produtos adequados. Mais do que isto, qualificar seus produtos e serviços, criar novos serviços e produtos adequados as demandas e expectativas percebidas. (ROZADOS; PIFFER, 2009, p. 179). 
No segundo, Gusmão et al. (2011) realizaram uma pesquisa de satisfação dos usuários com vistas a construir um diagnóstico situacional. Na pesquisa, constaram perguntas referentes a: qualidade de atendimento, visita orientada, frequência e motivo das visitas a biblioteca, qualidade de produtos/serviços ofertados, acervo bibliográfico, layout e sinalização da biblioteca, conforto do ambiente, divulgação das informações pertinentes à biblioteca, entre outros. As autoras concluem que as respostas servirão como "base de informações necessárias à elaboração de um plano de marketing para a referida Biblioteca." (GUSMÃO et al., 2011, p. 264).

\section{CONCLUSÃO}

Após examinar as publicações encontradas nos periódicos brasileiros de Ciência da Informação, percebe-se que, apesar do pequeno número de artigos encontrados, os bibliotecários estão em busca de transformar seus ambientes em locais mais atrativos e contam com ações de marketing para isso.

Com base nos resultados encontrados, as bibliotecas estão relatando a utilização do marketing no que diz respeito a:

- fornecer trocas com seus usuários - no qual bibliotecas oferecem aquilo que os usuários desejam e recebem confiança e lealdade em troca;

- escutar o usuário - identificando necessidades e desejos;

- implementar o endomarketing - com vistas a deixar o cliente interno satisfeito para que o mesmo consiga atender o cliente externo da melhor forma;

- repensar os sistemas de bibliotecas - existindo a demanda de um sistema que armazene informações pertinentes ao histórico do usuário;

- realizar o marketing cultural - permitindo as empresas que invistam nas bibliotecas;

- promover eventos - desenvolvendo agenda cultural com o intuito de chamar o usuário para dentro da biblioteca;

- aplicar a promoção e comunicação de serviços e produtos - investindo em divulgação e capacitação de seus usuários; e

- incorporar o marketing pessoal - fazendo com que haja a valorização da profissão, onde o bibliotecário buscará o aprimoramento profissional, traçara contatos

\begin{tabular}{l|l|l|l|l|l|l|}
\hline (C) Rev. digit. bibliotecon. cienc. inf. & Campinas, SP & v.11 & n.3 & p.30-45 & set./dez. 2013 & ISSN 1678-765X \\
\hline
\end{tabular}


com pessoas influentes, desenvolverá a habilidade da comunicação, etc.

O marketing como filosofia gerencial foi um dos assuntos mais abordados. Pressupondo que as bibliotecas estejam de fato, reorganizando a forma de gerir estas organizações, certamente uma gestão com foco no usuário, conforme a doutrina pregada pelo marketing.

O objetivo da pesquisa foi alcançado, visto que se conseguiu mapear de que forma as bibliotecas tem aplicado as ações de marketing em suas rotinas. Além da realização das análises de experiências que foram relatadas como sucesso.

Até o presente momento, o tema que serviu de base para criação deste estudo, encontra-se muito tímido. É necessário que os gestores de bibliotecas se interessem pelas ações mercadológicas, a fim de cumprirem com eficiência e eficácia suas missões e que relatem suas experiências, para assim servir de exemplo para as demais. Mais do que nunca é hora das bibliotecas livrarem-se de seus estigmas conservadores e transformarem-se em ambientes atrativos. 


\section{REFERÊNCIAS}

AMARAL, Sueli Angelica do. Os 4Ps do composto de marketing na literatura de ciência da informação. Transinformação, Campinas, v.12, n.2, p. 51-50, 2000. Disponível em: <http://revistas.puc-campinas.edu.br/transinfo/index.php>. Acesso em: 27 fev. 2012.

AMARAL, Sueli Angelica do. Marketing no ciberespaço: o desafio profissional das unidades de informação brasileiras no contexto da sociedade da informação. Revista de Biblioteconomia de Brasília, v.23/24, n.1, p.69-88, 1999/2000. Disponível em: <www.brapci.ufpr.br/download.php?dd0=17784>. Acesso em: 19 fev. 2012.

AMARAL, Sueli Angelica do. Gestão da informação e do conhecimento nas organizações e a orientação de marketing. Informação \& Informação, v.13, n.esp, p. 52-70, 2008. Disponível em: <http://www.uel.br/revistas/uel/index.php/informacao/article/view/1841>. Acesso em: 25 fev. 2012.

AMARAL, Sueli Angelica do. Marketing da informação: entre a promoção e a comunicação integrada de marketing. Informação \& Sociedade, João Pessoa, v.18, n.1, p.31-44, 2008. Disponível em: <http://www.ies.ufpb.br/ojs2/index.php/ies/article/view/1636/1637>. Acesso em: 20 fev. 2012.

American Marketing Association (AMA). Definition of marketing. Disponível em: <http://www.marketingpower.com/AboutAMA/Pages/DefinitionofMarketing.aspx>. Acesso em: 6 fev. 2012.

ANDRETTI, Cristiani Regina; CALEGARO, Édina Maria; MACHADO, Marli. Da lagarta para borboleta: ação cultural como estratégia de marketing no sistema integrado de bibliotecas da UNIVALI - SIBIUN. Revista ACB, v.13, n.1, p. 189-200, 2008. Disponível em: <http://revista.acbsc.org.br/index.php/racb/article/viewArticle/542>. Acesso em: $27 \mathrm{fev}$. 2012.

ANGELO, Edna da Silva; ZIVIANI, Fabricio. Marketing informacional em unidades de informação. DataGramaZero, Rio de Janeiro, v.12, n.3, 2011. Disponível em: <http://www.dgz.org.br/ago11/Art_05.htm>. Acesso em: 21 fev. 2012.

ARAÚJO, Wagner Junqueira de. Ferramentas para promoção em Web sites de unidades de informação. Revista de Biblioteconomia de Brasília, Brasília, v. 23/24, n.1, p. 89-108, 1999/2000. Disponível em: <www.brapci.ufpr.br/download.php?dd0=12280 >. Acesso em: 20 fev. 2012.

ARAÚJO, Walqueline da Silva; SILVA, Márcio Bezerra da; SILVA, Alzira Karla Araújo da. $\mathrm{O}$ uso do marketing na comunicação de produtos e serviços em unidades de informação: o caso da seção de multimeios da biblioteca central da UFPB. Biblionline, João Pessoa, v.7, n.2, p.73-88, 2011. Disponível em: <www.biblionline.ufpb.br/ >. Acesso em: 20 fev. 2012.

BAPTISTA, Sofia Galvão; COSTA, Maíra Murrieta; VIANA NETA, Maria Altair Vilanova. Marketing para promoção de produtos e serviços de informação: estudo de caso da biblioteca da presidência da republica. Revista Digital de Biblioteconomiae Ciência da Informação, Campinas, v.6, n.2, p.83-104, 2009. Disponível em: <http://www.sbu.unicamp.br/seer/ojs/index.php/sbu_rci/article/view/424>. Acesso em: 23 fev. 2012.

BARDIN, Laurence. Análise de conteúdo. Lisboa: Edições 70, 1979.

BASTA, Darci. et al. Fundamentos de marketing. Rio de Janeiro: FGV, 2006. 
CHURCHILL, Gilbert; PETER, J. Paul. Marketing : criando valor para os clientes. São Paulo: Saraiva, 2010.

DIAS, José Heládio Costa; DUARTE, Emeide Nóbrega. Marketing e endomarketing na biblioteca central da UFPB: subsídios para uma ação na divisão de serviços ao usuário. Biblionline, João Pessoa, v.6, n.1, p.25-52, 2010. Disponível em:<www.biblionline.ufpb.br/ >. Acesso em: 20 fev. 2012.

DUARTE, Emeide Nóbrega; SILVA, Espedito Pedro; ZAGO, Célia Cristina. Gestão do conhecimento: revelações da produção científica. Informação e Sociedade: estudos, João Pessoa, v. 14, n. 2, p. 173-200, jul./dez. 2004.

GIL, Antônio Carlos. Como elaborar projetos de pesquisa. São Paulo: Atlas, 1991.

GUSMÃO, Alexandre Oliveira de Meira. et al. Perspectivas para o marketing de relacionamento na biblioteca central da Universidade Federal de Mato Grosso. Revista ACB, Florianópolis, v.16, n.1, p. 250-268, 2011. Disponível em: <http://revista.acbsc.org.br/index.php/racb/article/viewArticle/748>. Acesso em: 21 fev. 2012.

JOB, Rejane Cristina. Vendem-se bibliotecas: estratégias de marketing cultural utilizadas pelas bibliotecas públicas do RS. Em Questão, Porto Alegre, v.10, n.2, p. 449-465, 2004. Disponível em: <http://seer.ufrgs.br/EmQuestao/article/view/107>. Acesso em: 28 fev. 2012.

KOTLER, Philip; LEE, Nancy. Marketing no setor público. Porto Alegre: Bookman, 2007.

LIMA, Suely Pedrosa da Silva; SILVA, Alzira Karla Araújo. O bibliotecário e o marketing pessoal na biblioteca do UNIPÊ: instrumento de promoção profissional no mercado de trabalho. Biblionline, João Pessoa, v.3, n.1, 22 p., 2007. Disponível em: <http://dci2.ccsa.ufpb.br:8080/jspui/handle/123456789/174>. Acesso em: 26 fev. 2012.

LUCAS, Elaine de Oliveira; SOUZA, Nicole Amboni. Disseminação seletiva da informação em bibliotecas universitárias sob o prisma do Customer Relationship Management. Informação \& Informação, Londrina, v.12, n.1, 17 p., 2007. Disponível em: <http://www.uel.br/revistas/uel/index.php/informacao/article/view/1745>. Acesso em: 29 fev. 2012.

NEVES, Guilherme Luiz Cintra; SOUZA, Nicole Amboni de; ELAINE, Rosangela de Oliveira Lucas. Aplicativos de gestão de bibliotecas e a utilização do Customer Relationship Management. Revista ACB, Florianópolis, v.11, n.1, p.111-127, 2006. Disponível em:

<http://revista.acbsc.org.br/index.php/racb/article/viewArticle/470/595>. Acesso em: 29 fev. 2012.

OLIVEIRA, Ângela Maria de. A internet como ferramenta de marketing nas bibliotecas. Informação \& Informação, Londrina, v.7, n.2, p. 105-112, 2002. Disponível em: <http://www.uel.br/revistas/uel/index.php/informacao/article/view/1702>. Acesso em: 27 fev. 2012.

OLIVEIRA, Ângela Maria de; PEREIRA, Edmeire. Marketing de relacionamento para gestão de unidades de informação. Informação \& Sociedade, João Pessoa, v.13, n.2, p. 13-36, 2003. Disponível em: <www.ies.ufpb.br/ >. Acesso em: 26 fev. 2012.

OLIVEIRA, Daniela Assis de. Utilização de um plano estratégico de marketing como instrumento decisório na gestão da biblioteca do SENAC de Florianópolis. Revista ACB, Florianópolis, v.13, n.1, p.174-188, $2008 . \quad$ Disponível em: <http://revista.acbsc.org.br/index.php/racb/article/viewArticle/548>. Acesso em: 27 fev. 2012. 
OLIVEIRA, Sitas Marques de. Marketing e sua aplicação em bibliotecas: uma abordagem preliminar. Ciência da Informação, Brasília, v.14, n.2, p.137-47, jul./dez. 1985. Disponível em: 〈http://revista.ibict.br/index.php/ciinf/article/view/1439/1057>. Acesso em: 22 fev. 2012.

ROZADOS, Helen Frota; PIFFER, Bárbara Pilatti. Pesquisa de marketing e estudos de usuário: um paralelo entre os dois processos. Em Questão, Porto Alegre, v.15, n.2, p.169182, 2009. Disponível em: 〈http://seer.ufrgs.br/EmQuestao/article/view/10387>. Acesso em: 24 fev. 2012.

SILVA, Alzira Karla Araújo da; MOREIRA, Elaine Cristina; DUARTE, Emeide Nóbrega. Aplicação de técnica de endomarketing em biblioteca universitária. Informação \& $\begin{array}{llllll}\text { Sociedade, } & \text { v.10, n.2, } & 8 & \text { p., } & 2000 . & \text { Disponível em: }\end{array}$ <http://www.ies.ufpb.br/ojs2/index.php/ies/article/view/334/256>. Acesso em: 22 fev. 2012.

SILVA, Antônio Felipe Galvão da. Marketing em unidades de informação: revisão crítica. Revista de Biblioteconomia de Brasília, v. 23/24, n. 1, p. 5-24,1999/2000. Disponível em: <www.brapci.ufpr.br/download.php?dd0=12277 >. Acesso em: 21 fev. 2012.

\section{Como citar este artigo:}

CATIVELLI, Adriana Stefani. Marketing aplicado em bibliotecas: análise de conteúdo dos artigos publicados em periódicos da ciência da informação. Rev. digit. bibliotecon. cienc. inf., Campinas, SP, v.11, n.3, p.30-45, ago/nov. 2013. ISSN 1678-765X.

Disponível em: <http://www.sbu.unicamp.br/seer/ojs/index.php/rbci> 